\title{
Gender Inequality in Higher Education in China and Solutions
}

\author{
Yuxuan Liu ${ }^{1, *}$ \\ ${ }^{1}$ Jiaonan No.1 High School of Qingdao West Coast New Zone \\ ${ }^{*}$ Corresponding author. Email: guanghua.ren@gecacademy.cn
}

\begin{abstract}
The realization of educational equality is the basic performance of people-oriented. At present, in China, there are still many problems in the field of higher education that restrict the development of higher education and hinder gender equality in education. How to dig out the root cause of the gender difference in higher education and find an effective solution to the gender difference in education according to social practice is not only an important economic problem in Current Chinese society, but also an important educational theory and practice problem. This article uses various research methods to explore the current inequality of higher education in China, the reasons and positive solutions for that. This article contributes to solving the inequality of higher education in China in the future and benefit more Chinese people.
\end{abstract}

Keywords: Gender equality, Higher education, Education resources

\section{INTRODUCTION}

Gender inequality, in a broad sense, refers to the existence of gender bias, refers to the unequal treatment of members of one sex against members of another sex. The specific definition of gender inequality is very broad, mainly from the perspective of evolutionary psychology, social definition and cultural definition. The concept of gender inequality is objectively defined in all aspects.

\subsection{From the perspective of evolutionary psychology}

Evolutionary psychology predicts that there will be no differences between the sexes if they face exactly the same adaptive challenges. Physically, dominant men have more access to women, while less aggressive men have less chance of reproducing. In that case, the long history of human evolution has increased male aggression and dominance [1]. Evolutionary psychology does help explain human's similarities and differences. However, it can't predict cultural variations in human marriage patterns or explain why culture can influence people's behavior patterns over just a few decades. Evolution is not genetic determinism. The most important trait nature which has been given to people is the ability to adapt, to learn and change.

\subsection{From the perspective of culture}

Culture is anything that is shared by large groups of people which can be passed down from generation to generation, including ideas, attitudes and traditions. Like living things, culture is diverse. It competes for resources and evolves with the times. The influence of culture can be vividly illustrated by the differences in gender roles across time and place [2].

Although gender inequality still exists today, the gender gap has narrowed. Such a large amount of crosscultural change in such a short period of time shows that evolution and biology do not solidify gender roles and gender roles can also be influenced by time.

Moreover, women also have conflicts between family roles and social roles. In the talent market, with the increasingly fierce competition for jobs, the trend of thought advocating women's return to the family is quietly rising. Highly educated professionals, especially women, have the contradiction between starting a family and starting a career.

\subsection{From the perspective of society}

How are traditions passed on from generation to generation? The more influential hypothesis is the "parenting theory", which holds that the way parents 
raise their children determines who they become [3]. However, research shows that although a child's personality is shaped by parental example and nurturing, the differences between children raised in the same family are no less than the differences between two children randomly selected from a large number of families. Genes account for about 50 percent of individual differences in personality traits, shared environmental influences account for 0 to 10 percent. In addition, peer influence accounts for 40 to 50 percent [4]. Children are often most concerned not with what their parents think, but with what their peers think. Most of the culture they learn, including games, musical tastes, accents and even bad language, comes from their peers. The influence of parents on children, though great, is mostly very indirect; Peers, especially older peers, have a very direct influence on children's behavior [5]

In addition, there is gender stereotype in the society. Gender stereotype is a general view or prejudice against the personality characteristics, appearance, behavior and the role of a gender [1]. Stereotypes can be positive or negative. Positive stereotypes, for example, teach males to be "strong" and females to be "gentle a kind". Negative stereotypes, such as "male indifference" and "female weakness" [6]. However, whether positive or negative stereotypes, their essence is the same, which may limit diversity, opportunities and ability development of different genders [7]. Gender stereotypes are everywhere in life. Teachers hold different expectations and different educational attitudes towards students of different genders in the educational environment, which will be consciously or unconsciously displayed in their teaching and contact with students. It may have a great impact on students' academic and career development [6].

One of the inequalities in women's higher education is the problem of subject selection, which is affected by the consciousness of gender division of labor. The traditional concept holds that femininity and scientism are only mutually exclusive. The traditional concept shows that women are emotional and intuitive so they are good at image and language thinking, while men are good at logical abstraction and are easier to get rid of the interference of subjective emotion. Keeping rational and objective, this concept has a profound impact on the traditional sense of gender division of labor. It also seriously hinders women's development in science, technology, engineering and other related fields.

\section{GENDER DIFFERENCES IN HIGHER EDUCATION}

\subsection{Unequal access of men and women to higher education}

The proportion of women receiving higher education shows a decreasing trend with the improvement of educational level [8]. The higher the level of education is, the fewer women there will be, the greater the difference between men and women will be. There are obvious class, regional and urban-rural differences in women's access to high-level education.

China has been vigorously advocating equality between men and women in driving, all rights, including education. In addition, according to the Statistics of Higher Education Yearbook, in 2010, in China's colleges and universities at all levels, male students accounted for $66.6 \%$ of the total number of students, while female students only accounted for $33.4 \%$. In 2018, male college students were 1.2 times more than female college students in China [8]

\subsection{Restrictions on women's choice of major}

Although women have a wider range of professional choices and they can develop in fields such as science, technology and economy. However, in the traditional sense of the so-called male disciplines, such as science, technology, agriculture and forestry, women still have obvious disadvantages [9]. In Colleges and universities deployed by the central government, compared with male students, female students choose more disciplines in language, literature and history, while relatively few in mechanics, engineering and agronomy [7].

In the statistics on the distribution of male and female proportion of college students in various disciplines in China in the 2020s, the data shows that the male proportion of science, engineering, medicine and agriculture students is obviously higher than that of female students. Among them, engineering male students account for the largest proportion, as high as $63.89 \%$. Art, history, economics, literature, law, philosophy and pedagogy are disciplines with more women than men. Among them, women in literature account for the most, accounting for $87.82 \%$ [8].

\subsection{Gender inequality in resources of high education}

\subsubsection{Gender differences in funding allocation}

At present, there are some problems in the construction of liberal arts laboratory in colleges and universities, such as insufficient attention, insufficient investment and poor management. Strengthening the construction of liberal arts laboratory in colleges and universities is the inevitable requirement of the development of new liberal arts [10]. This is of great significance to improve the teaching quality of liberal arts courses, promote academic innovation and enhance professional characteristics. At present, the effective strategies to promote the construction of liberal arts laboratory are to improve the consciousness, optimize 
the teaching staff, establish a scientific management model and promote the investment of funds [11].

\subsubsection{Gender differences in campus facilities and space allocation}

The use of campus facilities and space is a real scene that people can see, but the gender differences in facilities and space are often ignored by people [12]. According to the investigation results of the surrounding environment of the bishop building of Wuhan University, women's satisfaction with the campus environment is much lower than that of men [13]. The reason is that the internal space design of the campus environment ignores women's behavior needs. From the perspective of the use of public facilities, the public facilities with men's basic behavior needs can be guaranteed, leading to the fact that the public facilities are highly functional and concentrated. Oppositely, women's demand for public facilities is not well guaranteed, such as the lack of sunshades, street lamps and other facilities [14].

Colleges and universities should pay attention to the behavioral differences between men and women, improve the threat and inequality to women in the environment, and improve security [15].

\subsubsection{Inequality of job resources between men and women in Higher Education}

In teaching activities and job elections, women are obviously subordinate in most cases. In school organizations and school class activities, there is a serious gender imbalance in student organizations in colleges and universities. These activities have distinctive traditional role stereotypes, which is not conducive to the free, equal and all-round development of male and female students. According to the investigation and Research on the student union of Beijing Normal University, although there are more girls than boys in the University and the ratio of men to women reaches 3:7, most of the chairmen and ministers of the student union are men. Men are the leaders of the student union; women are non-main leaders and they were led by men [15].

\subsubsection{There is serious discrimination against women in employment}

Female employment discrimination refers to a social phenomenon that employers refuse to hire women or reduce the probability of employment due to gender reasons in the employment process. Female employment discrimination has always existed in the process of employment and job hunting due to the feudal traditional concept [16]. In addition, because of the unique physiological structure of women of giving childbirth, which may affect the normal operation of the company, many companies directly discriminate against female employment [17].

\section{SOLUTIONS}

\subsection{Increase the access to higher education to narrow gender differences}

First of all, from the perspective of enrollment opportunities in higher education, reducing gender differences should start with basic education, especially in promoting the equity of basic education, so as to ensure that girls have the same educational opportunities. The government should increase investment in basic education and improve the teaching level of primary and secondary school teachers, leading the result of reducing the impact of family factors on gender differences in primary and secondary school students' academic performance. At the same time, the society should actively publicize the idea of equality between men and women and trying its best to eliminate the concept of "son preference" in some families.

Secondly, from the perspective of the training process of higher education, girls should be encouraged to study hard, improve their personal quality, and cultivate their employability and entrepreneurial awareness. After all, human capital is the core factor of employment competitiveness. Moreover, women's comparative advantage in academic performance can make up for other deficiencies.

\subsection{Changes on female's selection of major}

Firstly, the society and colleges should provide women with more majors that they can choose. In education and society, teachers and government policies should encourage women to choose more majors in science and engineering. More and more women should participate in these "male fields" in traditional vision, which can also provide newer and broader perspectives for these fields. It is difficult for men to measure the integrity of a thing from a more comprehensive perspective. However, women will provide more meaningful and unique insights for lots of things because women have their own delicate feelings and special opinions. Government and society should strengthen efforts to cultivate women's interest and academic ability in science and engineering [18].

Secondly, colleges should appropriately improve the admission rate of women in vulnerable disciplines. In the traditional "male disciplines" such as science and engineering, government policies should appropriately improve the enrollment rate of women to increase the enrollment proportion of women. 


\subsection{Change the industrial and the economic structure}

At present, China's industrial structure is dominated by manual labor. Due to the physical differences between men and women, the proportion of men in industrial posts is often higher than that of women. From the perspective of the industry structure of graduates' employment, the government should speed up the adjustment of economic structure and change the economic growth model, especially speed up the development of modern service industry [19]. In that case, industries conducive to women's employment will develop faster, more and better in the long run.

From the perspective of the unit structure of graduates' employment, the more uncompetitive industries and units are, the more likely there is gender discrimination. The government should strengthen the management of talent recruitment in state organs, stateowned enterprises and institutions, then resolutely eliminate all forms of gender discrimination [19].

\subsection{Let women participate more in national decision-making}

At present, $82 \%$ of China's major national policies and political affairs are made by men. Government should vigorously encourage and support women to participate in national policies, legal discussions and other national political affairs. Government should also hire more female government staffs to increase the proportion of female staffs which more women can strive for women's rights in daily political life [20].

\section{CONCLUSION}

China's higher education often ignores the gender differences in teaching and resources. It takes the traditional gender perspective of "strong men and weak women" as the basis for resource allocation, leading to the fact that it lacks a lot of needs from the perspective of female. China's settings of higher education should pay more attention to the psychological differences between men and women and improve the inequality of women in studying. The distribution of teaching resources should take into account the differences between men's and women's needs; The colleges and universities should pay attention to the behavioral differences between men and women and give full play to women's enthusiasm in learning management; The government should pay attention to the differences between men and women and seek change in the unity of social position resources; The society should pay attention to the limitations and improvement of men and women in choosing majors to create a better environment for higher education with more equality.

\section{REFERENCES}

[1] Tian Qian. A study on Chinese women's mate selection tendency -- Based on the explanation of evolutionary psychology (Doctoral discrimination, Fudan University).

[2] Wang Fengyu (2013). Gender differences in appellation terms and their socio-cultural connotation. Youth, 000 (002), 154-155.

[3] Hentschel T,Hellman ME and Peus CV.(2019).The Multiple Dimensions of Gender Stereotypes.A Current Look at Men's and Women's Front.

[4] Ridley (2005). Innate and postnatal: genes, experience and what makes us human. Beijing University of Technology Press.

[5] Liu Huiqun (2009). Equity in Higher Education from a gender perspective. Journal of Jishou University (SOCIAL SCIENCE EDITION) (05), 131-135.

[6] Kahalon.R.Shnabel N and J.C.(2018)Positive stereotypes ,negative outcomes.Psychol,57.482502.

[7] Song Tao. Study on gender differences in higher education admission opportunities in China (Doctoral discrimination, Shanxi University).

[8] Wang Weiyi, \&amp; Li Jie. (2015). Multidimensional analysis of gender differences in higher education enrollment opportunities. Educational Research (08), 54-60.

[9] Guo Congbin, Zeng ManChao, \&amp; Ding Xiaohao. (2007). Gender differences in education and employment of science and engineering students in Chinese universities. Proceedings of the 2007 China Annual Conference on educational economics.

[10] Zhao Yahong, \&amp; Deng Yaowu. Importance and measures of strengthening the construction of humanistic literature resources. Library of Beijing Jiaotong University - the Fourth Symposium.

[11] Shi huishuang (2016). Research on the construction of liberal arts laboratories in Colleges and universities. Management and technology of small and medium-sized enterprises.

[12] Song Tao (2006). A review of the current situation of gender differences in higher education enrollment opportunities in China. China Youth Research, 000 (008), 57-60.

[13] Wang Fang, \&amp; Li Ziwei. (2021). Study on gender differences in public space on University Campus -- Taking Quanzhou campus of overseas 
Chinese University as an example. (2013-2), 120125.

[14] Li Suya, \&amp; Song Jufang. (2017). Discussion on the causes of the difference in the demand for public facilities under the condition of gender differences -- Taking the difference in the demand for public facilities between men and women around the bishop school building of Wuhan University as an example. Sichuan architecture, 037 (004), 4-5.

[15] Que Yi (2012). Research on the influence of gender differences on outdoor space design on University Campus (Doctoral disturbance, Huazhong Agricultural University).

[16] Zhai ting. (2013). Analysis of the influence of gender differences on career choice. Chinese times (next xunyan), 000 (011), 204-204206.

[17] Li Qi, \&amp; Duan still. (2019). Study on gender differences in higher education returns. Journal of Xinyang Agricultural College, 029 (001), 43-47,51.

[18] Wang Lihong. Research on the professional choice of female college students from the perspective of gender (medical discrimination, Shanghai Normal University).

[19] Qiao Xuebin, Yao Wenfan, \&amp; Zhao Dinghai. (2013). Interaction and co change: Research on the correlation between higher education structure, graduate employment structure and industrial structure. Journal of Southeast University (PHILOSOPHY AND SOCIAL SCIENCES EDITION), 000 (004), 122-126.

[20] Wang Naji (2008). Research on gender inequality in Chinese Politics: Women's political participation (Fudan University). 